
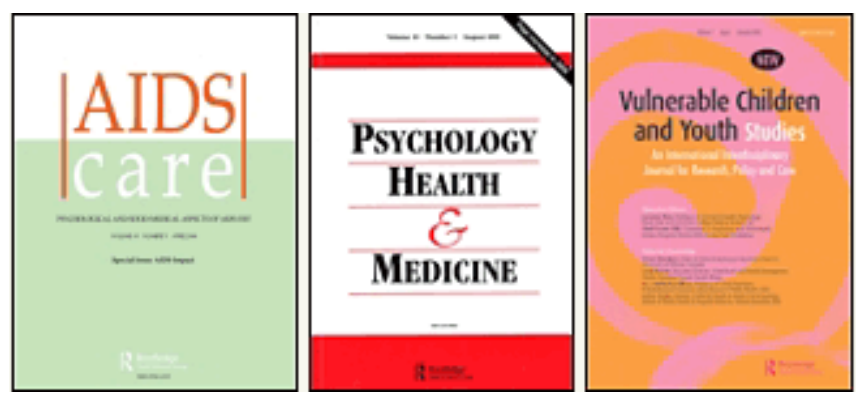

\title{
Poverty and psychological health among AIDS-orphaned children in Cape Town, South Africa
}

\begin{tabular}{|r|l|}
\hline Journal: & $\begin{array}{l}\text { AIDS Care - Psychology, Health \& Medicine - Vulnerable Children } \\
\text { and Youth Studies }\end{array}$ \\
\hline Manuscript ID: & AC-2008-03-0099.R1 \\
\hline Journal Selection: & AIDS Care \\
\hline Keywords: & children, orphans, psychological health, poverty, South Africa \\
\hline \multicolumn{2}{|l}{} \\
\hline
\end{tabular}

\section{S) ScholaroNE" \\ Manuscript Central}


Running head: POVERTY AND AIDS ORPHANS

Poverty and psychological health among AIDS-orphaned children

in Cape Town, South Africa

\begin{abstract}
: 125 words
Main text: 3,190 words
\end{abstract}

Tables: 3

Figures: 1 


\begin{abstract}
This study examined associations between AIDS-orphanhood status, poverty indicators, and psychological problems (depression, anxiety, post-traumatic stress, peer problems, delinquency, conduct problems) among children and adolescents in townships surrounding Cape Town, South Africa. One thousand and twenty-five children and adolescents completed standardized and culturally sensitive cross-sectional surveys. Children orphaned by AIDS had more psychological problems including depression, peer problems, post-traumatic stress, and conduct problems. Specific poverty indicators including food security, access to social welfare grants, employment in the household and access to school were associated with better psychological health. Poverty indicators mediated associations of AIDS-orphanhood with psychological problems. Food security showed the most consistent association with reduced psychological problems. Poverty alleviation measures have the potential to improve psychological health for AIDSorphaned children in South African townships.
\end{abstract}

Keywords: poverty, psychological health, orphans, HIV/AIDS 
Poverty and psychological health among AIDS-orphaned children in Cape Town

Orphanhood is a major consequence of the AIDS epidemic in South Africa, with an estimated 2.2 million AIDS-orphaned children - 11,188 per 100,000 children - by 2015 (Dorrington, Johnson, Bradshaw, \& Daniel, 2005; Statistics SA, 2006). Evidence suggests that AIDS-orphaned children are at particular risk for psychological distress compared with non-orphans (Nyamukapa et al., 2008). A recent review (Cluver \& Gardner, 2007a) found raised rates of depression (Makame, Ani, \& McGregor, 2002; Sengendo \& Nambi, 1997), anxiety (Atwine, Cantor-Graae, \& Bajunirwe, 2005; Pelton \& Forehand, 2005), post-traumatic stress (Cluver, Gardner, \& Operario, 2007; Makaya et al., 2002) and peer relationship difficulties (Bhargava, 2005; Cluver, Gardner, \& Operario, 2008) among AIDS orphans in sub-Saharan Africa.

Distress from orphanhood may be exacerbated due to financial difficulties associated with parental illness and death (Silverman, 2000; Stoppelbein, 2000). Familial AIDS illness has been shown to determine increased household poverty, food insecurity and unemployment (Booysen, 2002). AIDS-orphaned children may experience pressures to assume adult responsibilities such as caregiving or entering formal or informal labor sectors, which can contribute to lower levels of school enrollment and attendance among AIDS-orphaned children compared with other groups (Gray et al., 2006). Indeed, in a qualitative study of 120 orphaned children and caregivers, participants identified food insecurity, school non-attendance, and lack of welfare grants as substantial threats to health (Cluver \& Gardner, 2007b). 
General literature on child bereavement has suggested that poverty can be an additional stressor, independent of parental loss, on children's psychological well-being (Dowdney, 2000). No known studies have examined this dynamic among AIDSorphaned children in developing world settings, such as South African townships where environmental stressors of AIDS-bereavement and acute poverty co-exist.

The present study examines 1025 young people aged 10-19 recruited using targeted sampling from deprived urban areas in South Africa. It compared children orphaned by AIDS to children orphaned by non-AIDS causes and non-orphaned children. Prior analyses have indicated that AIDS-orphaned children experience heightened psychological distress compared to other children (Cluver et al., 2007). The aims of this paper are two-fold: First, to examine associations between orphanhood, poverty, and psychological distress in this sample of South African young people; and second, to assess whether poverty mediates the association between AIDS-orphanhood status and psychological distress. Insight into these associations can inform public health and policy debates on the relevance of poverty alleviation programs for psychological outcomes of orphaned children in South Africa.

Method

\section{Participants}

Participants were recruited between 2005-2006 from 9 schools, 18 NonGovernmental Organisations (NGOs) and door-to-door sampling. Targeted community sampling strategies were used to recruit adolescent children orphaned due to AIDS, adolescent children orphaned due to other causes of parental death, and non-orphan adolescents, matched according to gender, age, and location. Recruitment strategies over- 
sampled from groups unlikely to be included in school-based studies, including streetchildren (via shelters and feeding schemes), child-headed and youth-headed households, and non-school-attendees. Social services and NGOs facilitated access to participants who were not enrolled in school. Eligibility criteria adopted the UN definition of orphanhood as loss of one or both parents (UNAIDS, 2004), and the World Health Organisation definition of adolescence as 10-19 years (World Health Organisation, 2003).

Recruitment efforts focused on $1470 \mathrm{~km}^{2}$ of deprived urban settlements of Cape Town, South Africa, in neighbourhoods formerly designated for 'black Africans' under apartheid. Study areas were characterized by high population density, for example 67 people/hectare in Khayelitsha (Statistics South Africa, 2003). The Cape Flats experience extreme levels of property crime, rape and violent crime (South African Police Services, 2004). Average income is less than ZAR1500 (UK£100) per month. At the 2001 Census, unemployment in Khayelitsha was $67 \%$, and $51 \%$ of residents lived in informal dwellings (Statistics South Africa, 2003). Data collection took place in both informal and formal settlements.

At the time of data collection, all schools were fee-paying. There are a large number of primary schools located throughout residential settlements, but functional illiteracy was $15 \%$ in 2001. In a 2006 survey, $18 \%$ of Khayelitsha respondents reported distance to health facility as a problem in accessing services, and $28 \%$ reported payment for health services as difficult (Department of Social Development, 2006).

Recruitment strategies yielded a sample of 1025 young people aged 10-19, of whom 425 were orphaned by AIDS, 241 orphaned by non-AIDS causes, and 278 were 
not orphaned. Orphaned children lived with a range of primary caregivers. For AIDSorphaned children, $32 \%$ lived with a surviving parent (compared to $56 \%$ of other-orphans and $74 \%$ of non-orphans), $21 \%$ lived with a grandparent ( $8 \%$ of other-orphans and $9 \%$ of non-orphans), $33 \%$ lived with another extended family member, including an adult sibling (20\% of other-orphans and $8 \%$ of non-orphans), $7 \%$ lived in a child-headed household (6\% of other-orphans and $1 \%$ of non-orphans), and 2-3\% of all groups lived with a non-relative primary caregiver. Numbers of streetchildren (5\% of AIDS-orphans, $7 \%$ other-orphans, $6 \%$ non-orphans) were purposively matched across all groups, as no reliable data is available on this population.

\section{Procedure}

Participants were screened for study eligibility and underwent informed consent procedures. Informed consent was gained from primary caregivers or from appropriate adults (i.e. social workers) in situations where children had no caregiver. Interviewers were 5 local, Xhosa-speaking social workers, psychologists or community health workers with prior experience working with AIDS-affected children. Interviewers received additional training on survey administration and research ethics. Children completed face-to-face survey interviews lasting 40-60 minutes. Interviews were designed and piloted to be child-focused, and included games, cartoons and vignettes. Interviews took place in schools, homes and community centres. To exclude children undergoing acute bereavement, participants who had experienced orphanhood status in the previous 6 months were not interviewed. Following the interview, participants received light refreshments and a certificate of thanks. Confidentiality was maintained, except where 
children were at risk of significant harm or requested assistance. Research procedures received IRB approval from Oxford University, the University of Cape Town, and the Department of Education-Western Cape.

\section{Measures}

Parental Death was assessed using the 'verbal autopsy' method, which improves on inaccuracies in official death certificates, described in previous studies of adult mortality in South Africa (Hosegood, Vanneste, \& Timaeus, 2004). In a South African validation study, sensitivity for adult communicable diseases was found to be $89 \%$, specificity was $93 \%$ and positive predictive value $76 \%$ (Kahn, Tollman, Garenne, \& Gear, 2000). Parental death due to AIDS was determined by the presence of 3 or more AIDS-defining illnesses, such as oral candidiasis, Kaposi's sarcoma or HIV-wasting syndrome (World Health Organisation, 2005); additional indicators of AIDS death included death of both parents and/or infant deaths of siblings from AIDS-defining illnesses. Non-AIDS causes of deaths included road accidents, suicide, and homicide. Child report on cause of parental death was corroborated by teachers, social workers and surviving family, and where diagnoses were in doubt, symptoms were reviewed by two independent medical practitioners. Using these criteria, 81 orphans $(11 \%)$ were excluded from present analyses, due to unknown or uncertain cause of parental death, and these cases were removed from present analyses.

Depression was measured using the Child Depression Inventory (CDI short form) (Kovacs, 1992). It has been widely used in South Africa, shows good psychometric properties, and has comparable results with the full CDI (Kovacs, 1992). 
Anxiety was measured using the 28-item Children's Manifest Anxiety ScaleRevised (R-CMAS) (Reynolds \& Richmond, 1978). This shows good reliability and validity (Gerard \& Reynolds, 1999) and has been used in South Africa (Wild, Flisher, Laas, \& Robertson, 2006, July).

Peer problems were measured using the 5-item peer problems subscale of the Strengths and Difficulties Questionnaire (SDQ) (Goodman, 1997). The SDQ has strong psychometric properties, has been translated into 51 languages, including Xhosa, and has been validated in many developing countries (Goodman, Renfrew, \& Mullick, 2000b).

Post-traumatic stress was measured using the 28-item 'Child PTSD Checklist', which has been used extensively in Cape Town (eg. Seedat, Nyamai, Njenga, Vythilingum, \& Stein, 2004). The text-based checklist was accompanied by cartoons derived from the Levonn/Andile PTSD scale (Richters, Martinez, \& Valla, 1990), which was found accessible for Xhosa-speaking adolescents in Cape Town (Ensink, Robertson, Zissis, \& Leger, 1997).

Conduct problems were measured using the 5-item 'conduct problems' SDQ subscale SDQ (Goodman, 1997) and the 11-item delinquent subscale of the Youth SelfReport (Achenbach, 1991). The YSR has good psychometric properties (Achenbach \& Rescorla, 2001; Song, Singh, \& Singer, 1994), and has been used with AIDS-orphaned children (Forehand et al., 2002), and in South Africa (Van der Merwe \& Dawes, 2000; Wild et al., 2006, July).

Demographic and environmental characteristics included age, gender, age at orphanhood, household size, migration and number of moves between homes. 
Poverty indicators included access to school, food security, employment in the household, and receipt of welfare grants. Each poverty indicator represented the focus of distinct poverty alleviation programmes in South Africa. School enrolment were ascertained from school registers or social workers, corroborated by the child and coded dichotomously as 'currently enrolled/not enrolled'. Food security was measured as number of days (0-7) without food in the past week, following studies with AIDSorphaned children in Tanzania (Makame et al., 2002). Following the UN definition of 'food security' as constant and adequate nutrition (UNESCO, 1996) and in recognition of poor overall food security in the research area (Cousins, 2004), an 'acceptable' threshold was set of 'at least 5 days in the past week with sufficient food', and coded dichotomously as 'secure/not secure'. Household employment was assessed by 'Does anyone in your home have a job?' and was coded dichotomously and corroborated by adult report. Receipt within the household of each of the possible welfare grants available in South Africa (child support grant, foster care grant, pension, war veterans grant, care dependency grant, disability grant, social relief of distress, and grant in aid) were coded as dichotomous variables and corroborated by caregiver or social worker report. They were then combined to determine household receipt of any grant, and coded dichotomously.

Analysis

Although all scales had been previously used in studies with South African children, no standardized psychological scales for this age group have been validated in Southern Africa, and so clinical cut-off scores reflecting Western norms were considered 
inappropriate. For this reason, all analyses used continuous scores for psychological variables.

Differences between groups (AIDS-orphans, other-orphans, non-orphans) on sociodemographic characteristics and poverty indicators (levels of food security, employment, welfare grants and school access) were assessed using Chi-square tests for categorical variables or one-way ANOVAs for continuous variables. Associations between poverty indicators and mental health outcomes were examined using independent sample t-tests.

Multivariate linear regression analyses were used to assess associations between each orphan status variable (orphaned due to AIDS and orphaned due to other causes, compared with non-orphaned children) with each mental health outcome (depression, anxiety, post-traumatic stress, peer problems, delinquency, conduct problems). Two models are presented for each outcome. Model 1 presents associations between orphan status and mental health outcome, adjusting for any sociodemographic co-factors (i.e. age, gender, age at orphanhood, household size, internal migration within South Africa, number of moves between homes) that were associated at $\mathrm{p}<.20$ with each respective outcome in univariate analyses (Hosmer \& Lemeshow, 1989). Model 2 further adjusted for poverty indicators expected to mediate the association between orphan status and mental health. A 'poverty index' score was derived by summing the four variables of attending school, food security, household employment, and any social security transfer, and this was used in all multivariate regressions. Following from Baron \& Kenny (1986), reductions in coefficients between Model 1 and Model 2 were indicative of a mediational effect of poverty on the association between orphan status and mental health outcome 
(Baron \& Kenny, 1986). We then used the Sobel test (Sobel, 1982) to assess the mediating effect of a combined poverty index on the relationship between orphanhood status and psychological outcomes (Figure 1).

Data were analyzed using SPSS (Version 14.0). Mean imputation was used in case of missing values for psychological scales. For demographic variables, missing values were negligible as interviewers were trained to ensure all items were completed. All tests were two-tailed. To reduce likelihood that results capitalize on error, we held our test of statistical significance at the $\mathrm{p}<.01$ level.

Results

Orphan status, sociodemographic characteristics, and poverty

Average age of participants was 13.4 years, and significant age differences were observed between each group with AIDS-orphaned children older than other orphans and non-orphaned children (Table 1). Overall, the sample was 53\% male and $47 \%$ female, with no gender differences in AIDS-orphanhood.

AIDS-orphaned children were more likely to have lost both parents and were older at first parental bereavement than children orphaned by other causes. Among AIDSorphans, $59 \%$ were maternally bereaved, $66 \%$ paternally bereaved, and $25 \%$ doubly bereaved. Among non-AIDS orphans, $28 \%$ were maternally bereaved, $83 \%$ paternally bereaved, and $12 \%$ doubly bereaved.

Table 1 also shows associations between orphanhood status and poverty indicators. Overall school attendance was high, though AIDS-orphaned children were less likely to be enrolled than other-orphaned or non-orphaned children. AIDS-orphaned children were more likely to report food insecurity and household unemployment than 
other-orphaned children; non-orphans reported relatively high levels of food security and household employment. All participants lived in poor households eligible for meanstested grants; however, grant uptake was variable. AIDS-orphaned children were less likely to live in a household accessing any grant compared with other-orphans and nonorphans. Both AIDS-orphans and other-orphans lived in smaller households and were less likely to live in formal dwellings compared with non-orphans.

\section{Poverty and mental health outcomes}

Table 2 shows results of t-tests comparing mental health outcomes by each poverty indicator. Access to school, food security, employment in the household and receipt of any welfare grant were each associated with lower scores on depression, anxiety, peer problems, post-traumatic stress, delinquency and conduct problems.

Multivariate associations between orphan status, poverty, and mental health

Table 3 presents multivariate models on (a) the association between orphanhood status and each psychological outcome (controlling for relevant socio-demographic cofactors), and (b) associations between orphanhood status, poverty indicators, and each psychological outcome. Each model compared both orphan groups (AIDS orphans and other orphans) with non-orphans as the reference group.

Controlling for relevant socio-demographic co-factors (age, gender, household size and more than 2 moves between homes), orphanhood by AIDS was significantly related to depression $(\mathrm{p}<.01)$, peer problems $(\mathrm{p}<.01)$, post-traumatic stress $(\mathrm{p}<.01)$ and moderately related to conduct problems $(\mathrm{p}<.05)$. In the adjusted model controlling for poverty indictors, the association between AIDS-orphanhood and psychological distress was completely eliminated for depression and conduct problems, and remained 
significant but was weakened for peer problems and PTSD. Orphanhood by AIDS was not associated with anxiety or delinquency in either model. Orphanhood by other causes was not associated with any mental health problems in either unadjusted or adjusted models.

\section{Tests of Mediation}

We directly tested whether the derived poverty index of the four poverty alleviation factors measured (school access, food security, household employment and access to welfare grants) mediated the association of AIDS-orphanhood and psychological outcomes. We used the Sobel test for mediation (Sobel, 1982). Results showed that the poverty index mediated the association of AIDS-orphanhood with depression $(\mathrm{p}<.01)$, peer problems $(\mathrm{p}<.01)$, PTSD $(\mathrm{p}<.01)$, delinquency $(\mathrm{p}<.01)$, and conduct problems $(\mathrm{p}<.01)$.

Discussion

Children who are orphaned due to parents' AIDS-illness experience higher risk for adverse psychological outcomes, and interventions to address these problems are necessary. We have examined poverty factors that potentially explain the association between AIDS-orphanhood and psychological problems, focusing on school access, food security, household employment, and household receipt of welfare grants. When combined, this poverty index reduced the association of AIDS-orphanhood with peer problems and PTSD, and eliminated the association of AIDS-orphanhood with depression and conduct problems. Of the poverty indicators, food security appeared to have the strongest and most consistent effect on the association between AIDS-orphanhood and psychological problems. 
South Africa has recognized the multidimensional nature of child poverty (Noble, Wright, \& Cluver, 2006) and has launched a series of poverty alleviation programs, such as roll-out of free schooling. Our findings suggest that, as well as being valuable in their own right, these poverty programmes might potentially improve psychological outcomes for AIDS-orphaned children. However, reach of poverty-alleviation programs to intended beneficiaries can be variable (Department of Social Development, 2008), and so strategies for maximizing receipt of programs may be necessary.

We found that AIDS-orphaned children were consistently disadvantaged on all poverty indicators compared to other groups. Children orphaned by AIDS had higher school dropout, food insecurity, and lower adult employment in households than other groups. AIDS-orphans were less likely to live in a household receiving any state grant, which is likely to reflect limited access to welfare support rather than non-eligibility.

Findings of this study suggest potential interventions within South Africa's existing poverty-alleviation strategies. In the light of the consistent effects of food security, programs such as school feeding schemes, sustainable food and gardening projects, employment initiatives and targeted assistance for grant applications could have positive mental health impacts on AIDS-orphaned children. Many of these programmes are already being piloted. This study also builds on prior evidence from the developed world that increased poverty after parental death can be associated with increased psychological problems (Stoppelbein, 2000).

This study has a number of methodological limitations. First, identifying cause of parental death is problematic in a context of high stigma, low HIV-testing levels, and unreliable death certificates (Hosegood et al., 2004), although the verbal autopsy method 
was used to improve on official reports by using AIDS-defining illnesses and medical practitioner review to improve reliability of assessment. Second, use of cross-sectional data prohibits temporal or causal explanations; this study cannot tell us whether AIDSorphaned children were more disadvantaged in terms of poverty and welfare grants prior to orphanhood, or whether they experienced psychological problems prior to orphanhood. Third, interpretations of the mediational effect of poverty on the association between AIDS orphanhood and psychological problems must be interpreted with caution, as it is unclear whether AIDS-orphanhood directly led to increased poverty which then accounted for increased psychological problems. Determining direct and indirect effects of mediating variables may require more complex path analysis strategies, with additional data collection time points. These limitations can be addressed in future research by using multiple assessments, such as longitudinal studies of South African youth, and evaluating the impact of current poverty alleviation programs on outcomes among AIDS-orphaned children. Future studies could also valuably measure children's access to school uniform and school shoes, opportunity to do schoolwork, and economic activities undertaken by children.

Strengths of this study design and sampling should be noted. To date, this is the largest study known to explore psychological outcomes among South African children orphaned by AIDS compared to control groups of both non-orphans and children orphaned by non-AIDS causes. The study uses well-validated standardized scales with good psychometric properties. The study also included groups frequently omitted from community samples, such as children living on the streets, child-headed and youthheaded households. 
The post-apartheid South African government has implemented a range of poverty-alleviation policies aimed at improving well-being of deprived families. There is growing evidence of the positive effects of such policies on child well-being, such as improved school enrolment among recipients of the Child Support Grant (Case, Hosegood, \& Lund, 2005). This study suggests that programs that aim to reduce poverty, particularly by improving food security, have the potential to alleviate psychological distress for AIDS-orphaned children. 


\section{References}

Achenbach, T. (1991). Manual for the Youth Self-Report and 1991 Profile. Burlington, VT: University of Vermont.

Achenbach, T., \& Rescorla, L. (2001). Manual for the ASEBA School-Age Forms and Profiles. Burlington, VT: University of Vermont.

Atwine, B., Cantor-Graae, E., \& Bajunirwe, F. (2005). Psychological Distress among AIDS orphans in rural Uganda. Social Science and Medicine, 61(3), 555-564.

Baron, R., \& Kenny, D. (1986). The Moderator-Mediator Variable Distinction in Social Psychological Research: Conceptual, Strategic, and Statistical Considerations. Journal of Personality and Social Psychology, 51(6), 1173-1182.

Bhargava, A. (2005). AIDS epidemic and the psychological well-being and school participation of Ethiopian orphans. Psychology, Health and Medicine, 10(3), 263-275.

Booysen, F. (2002). Financial responses of households in the Free State province to HIV/AIDS-related morbidity and mortality. South African Journal of Economics, 70(7), 1193-1215.

Case, A., Hosegood, V., \& Lund, F. (2005). The reach and impact of Child Support Grants: evidence from KwaZulu-Natal. Development Southern Africa, 22(4), 467-482.

Cluver, L., \& Gardner, F. (2007a). Mental health of children orphaned by AIDS: A review of International and Southern African research. Journal of Child and Adolescent Mental Health, 19(1), 1-17.

Cluver, L., \& Gardner, F. (2007b). Risk and Protective Factors for psychological wellbeing of orphaned children in Cape Town: A qualitative study of children's views. AIDS Care, 19(3), 318-325.

Cluver, L., Gardner, F., \& Operario, D. (2007). Psychological distress amongst AIDSorphaned children in urban South Africa. Journal of Child Psychology and Psychiatry, 48(8), 755-763.

Cluver, L., Gardner, F., \& Operario, D. (2008). Effects of stigma and other community factors on the mental health of AIDS-orphaned children. Journal of Adolescent Health, $42,410-417$.

Cousins, B. (2004). Livelihoods, Vulnerability and Food Insecurity in Khayelitsha. Cape Town: University of the Western Cape and Food and Agriculture Organisation (UN). 
Department of Social Development. (2006). Nodal baseline survey: Khayelitsha results: South African Regional Poverty Network www.sarpn.org.za.

Department of Social Development. (2008). Review of the Child Support Grant: Uses, implementation and obstacles. Gauteng: Community Agency for Social Enquiry, UNICEF.

Dorrington, R., Johnson, L., Bradshaw, D., \& Daniel, T. (2005). The demographic impact of HIV/AIDS in South Africa. National and Provincial indicators for 2006. Cape Town: Centre for Actuarial Research, South African Medical Research Council and Actuarial Society of South Africa.

Dowdney, L. (2000). Annotation: childhood bereavement following parental death. Journal of Child Psychology and Psychiatry, 41(7), 819-830.

Ensink, K., Robertson, B., Zissis, C., \& Leger, P. (1997). Post-traumatic stress disorder in children exposed to violence. South African Medical Journal, 87(11), 1526-1530.

Forehand, R., Jones, D., Kotchick, B., Armistead, L., Morse, E., Simon Morse, P., et al. (2002). Noninfected children of HIV-infected mothers: a 4-year longitudinal study of child psychosocial adjustment and parenting. Behavior Therapy, 33, 579-600.

Gerard, A., \& Reynolds, C. (1999). Characteristics and applications of the Revised Children's Manifest Anxiety Scale. In M. Maruish (Ed.), The use of psychological testing for treatment and planning and outcomes assessment (2 ed., pp. 323-340). Mahwah: Lawrence Erlbaum.

Goodman, R. (1997). The Strengths and Difficulties Questionnaire: A research note. Journal of Child Psychology and Psychiatry, 38(5), 581-586.

Goodman, R., Renfrew, D., \& Mullick, M. (2000b). Predicting type of psychiatric disorder from Strengths and Difficulties Questionnaire (SDQ) scores in child mental health clinics in London and Dhaka. European Child and Adolescent Psychiatry, 9, 129134.

Gray, G., Van Niekerk, R., Struthers, H., Violari, A., Martinson, N., McIntyre, J., et al. (2006). The effects of adult morbidity and mortality on household welfare and the wellbeing of children in Soweto. Vulnerable Children and Youth Studies, 1(1), 15.

Hosegood, V., Vanneste, A., \& Timaeus, I. (2004). Levels and causes of adult mortality in rural South Africa: the impact of AIDS. AIDS, 5(18), 663-671.

Hosmer, D., \& Lemeshow, S. (1989). Applied logistic regression. New York: John Wiley \& Sons. 
Kahn, K., Tollman, S., Garenne, M., \& Gear, J. (2000). Validation and application of verbal autopsies in a rural area of South Africa. Tropical Medicine and International Health, 5, 824-831.

Kovacs, M. (1992). Children's Depression Inventory. Niagra Falls, NY: Multi-health Systems.

Makame, V., Ani, C., \& McGregor, S. (2002). Psychological well-being of orphans in Dar El-Salaam, Tanzania. Acta Paediatrica, 91, 459-465.

Makaya, J., Mboussou, F., Bansimba, T., Ndinga, H., Latifou, S., Ambendet, A., et al. (2002). Assessment of psychological repurcussions of AIDS next to 354 AIDS orphans in Brazzaville, 2001. Paper presented at the XIV International AIDS conference, Barcelona.

Noble, M., Wright, G., \& Cluver, L. (2006). Developing a child-focused and multidimensional model of child poverty for South Africa. Journal of Children and Poverty, 12(1), 39-53.

Nyamukapa, C., Gregson, S., Lopman, B., Saito, S., Watts, H., Monasch, R., et al. (2008). HIV-Associated Orphanhood and Children's Psychosocial Distress: Theoretical Framework Tested With Data From Zimbabwe. Amercian Journal of Public Health, 98(1), 133-141.

Pelton, J., \& Forehand, R. (2005). Orphans of the AIDS epidemic: an examination of clinical level problems of children. Journal of the American Academy of Child and Adolescent Psychiatry, 44(6), 585-591.

Reynolds, C., \& Richmond, B. (1978). What I think and feel: A revised measure of children's anxiety. Journal of Abnormal Child Psychology, 6, 271-280.

Richters, J., Martinez, P., \& Valla, J. (1990). Levonn: a cartoon-based interview for assessing children's distress symptoms: University of Maryland, NIMH.

Seedat, S., Nyamai, C., Njenga, F., Vythilingum, B., \& Stein, D. (2004). Trauma Exposure and Post-Traumatic Stress symptoms in urban African schools. British Journal of Psychiatry, 184, 169-175.

Sengendo, J., \& Nambi, J. (1997). The psychological effect of orphanhood: a study of orphans in Rakai district. Health Transitions Review, 7(Supplement), 105-124.

Silverman, P. (2000). Never too young to know: Death in children's lives. New York: Oxford University Press.

Sobel, M. (1982). Asymptotic intervals for indirect effects in structural equation models. In S. Leinhart (Ed.), Sociological methodology (pp. 290-312). San Francisco: JosseyBass. 
Song, L.-Y., Singh, J., \& Singer, M. (1994). The Youth Self-Report Inventory: A study of its measurement fidelity. Psychological Assessment, 6(3), 326-245.

Statistics SA. (2006). General Household Survey 2005. Pretoria: Statistics SA.

Statistics South Africa. (2003). Census 2001: Census Database. Pretoria.

Stoppelbein, L. (2000). Posttraumatic stress sypmtoms in Parentally Bereaved Children and Adolescents. Journal of the American Academy of Child and Adolescent Psychiatry, 39(9), 1112-1119.

UNAIDS. (2004). Children on the Brink 2004: A joint report of new orphan estimates and a framework for action. New York: UN.

UNESCO. (1996). Rome Declaration on World Food Security. Rome: Adopted by the World Food Summit at Rome, Italy, 13-17 November 1996.

Van der Merwe, A., \& Dawes, A. (2000). Prosocial and antisocial tendencies in children exposed to community violence. Journal of Child and Adolescent Mental Health, 12, 1937.

Wild, L., Flisher, A., Laas, S., \& Robertson, B. (2006, July). Psychosocial adjustment of adolescents orphaned in the context of HIV/AIDS. Poster presented at the International Society for the Study of Behavioural Development Biennial Meeting, Melbourne, Australia.

World Health Organisation. (2003). Strategic directions for improving the health of children and adolescents. Geneva: WHO.

World Health Organisation. (2005). WHO/Euro Report of the Technical Consultation on Clinical Staging of HIV/AIDS and HIV/AIDS Case Definitions for Surveillance.

Copenhagen: WHO. 
Table 1: Differences between orphanhood groups on sociodemographic and poverty variables

\begin{tabular}{|c|c|c|c|c|}
\hline & $\begin{array}{r}\text { Children } \\
\text { orphaned } \\
\text { by AIDS } \\
(n=425)\end{array}$ & $\begin{array}{r}\text { Children } \\
\text { orphaned by } \\
\text { other causes } \\
(n=241)\end{array}$ & $\begin{array}{r}\text { Non-orphaned } \\
\text { children } \\
(\mathrm{n}=278)\end{array}$ & $p$-value \\
\hline \multicolumn{5}{|l|}{$\begin{array}{l}\text { Socio-demographic } \\
\text { variables }\end{array}$} \\
\hline Age $(\mathrm{M}, \mathrm{SD})$ & $13.70(2.52)^{\mathrm{a}}$ & $13.38(13.38)^{\mathrm{b}}$ & $13.02(2.01)^{\mathrm{c}}$ & $<.01$ \\
\hline Female $(\%)$ & $50.6^{\mathrm{a}}$ & $43.2^{\mathrm{a}}$ & $46.4^{\mathrm{a}}$ & ns \\
\hline $\begin{array}{l}\text { Xhosa ethnicity- } \\
\text { overall sample }(\%)\end{array}$ & $98.1^{\mathrm{a}}$ & $96.7^{\mathrm{a}}$ & $96.4^{\mathrm{a}}$ & ns \\
\hline $\begin{array}{l}\text { Household size (M, } \\
\text { SD) }\end{array}$ & $4.78(1.93)^{\mathrm{a}}$ & $4.61(1.71)^{\mathrm{a}}$ & $5.25(2.02)^{b}$ & $<.01$ \\
\hline Informal dwelling (\%) & $43.0^{\mathrm{a}}$ & $43.0^{\mathrm{a}}$ & $29.1^{b}$ & $<.01$ \\
\hline Internal migration (\%) & $41.4^{\mathrm{a}}$ & $44.0^{\mathrm{a}}$ & $40.6^{\mathrm{a}}$ & ns \\
\hline $\begin{array}{l}\text { Moved b/w } 2 \text { or more } \\
\text { homes }(\%)\end{array}$ & $66.4^{\mathrm{a}}$ & $69.3^{\mathrm{a}}$ & $71.6^{\mathrm{a}}$ & ns \\
\hline Loss of mother $(\%)$ & $58.6^{\mathrm{a}}$ & $28.2^{b}$ & - & $<.01$ \\
\hline Loss of father $(\%)$ & $66.1^{\mathrm{a}}$ & $83.0^{\mathrm{b}}$ & - & $<.01$ \\
\hline $\begin{array}{l}\text { Loss of both parents } \\
(\%)\end{array}$ & $24.9^{\mathrm{a}}$ & $12.4^{b}$ & - & $<.01$ \\
\hline $\begin{array}{l}\text { Age, first bereavement } \\
(\mathrm{M}, \mathrm{SD})\end{array}$ & $10.1(3.82)^{\mathrm{a}}$ & $7.8(4.56)^{b}$ & - & $<.01$ \\
\hline $\begin{array}{l}\text { Poverty-related } \\
\text { variables }\end{array}$ & & & & \\
\hline Attending school (\%) & $93.9^{\mathrm{a}}$ & $97.1^{b}$ & $98.2^{b}$ & $<.01$ \\
\hline $\begin{array}{l}\text { Food security } 5+ \\
\text { days/week }(\%)\end{array}$ & $65.4^{\mathrm{a}}$ & $78.0^{\mathrm{b}}$ & $91.4^{c}$ & $<.01$ \\
\hline $\begin{array}{l}\text { Any employment in } \\
\text { household }(\%)\end{array}$ & $50.1^{\mathrm{a}}$ & $59.8^{b}$ & $77.3^{c}$ & $<.01$ \\
\hline Any welfare grant (\%) & $45.9^{\mathrm{a}}$ & $60.6^{b}$ & $64.7^{b}$ & $<.01$ \\
\hline
\end{tabular}

Note: $P$-values associated with one-way ANOVA or Chi-square test. Different superscripts reflect statistically different means $(p<.01)$ using post-hoc comparisons. 
Table 2: Associations between poverty-related factors and mental health outcomes

\begin{tabular}{|c|c|c|c|c|c|c|c|c|c|c|c|c|}
\hline & $\begin{array}{c}\text { Depression } \\
\mathrm{M}(\mathrm{SD})\end{array}$ & $p$ & $\begin{array}{l}\text { Anxiety } \\
M(S D)\end{array}$ & $p$ & $\begin{array}{c}\text { Peer } \\
\text { Problems } \\
\text { M (SD) }\end{array}$ & $p$ & $\begin{array}{c}\text { Post- } \\
\text { Traumatic } \\
\text { Stress } \\
\text { M (SD) }\end{array}$ & $p$ & $\begin{array}{l}\text { Delinquency } \\
\text { M (SD) }\end{array}$ & $p$ & $\begin{array}{c}\text { Conduct } \\
\text { Problems } \\
\text { M (SD) }\end{array}$ & $p$ \\
\hline & & $<.01$ & & $<.01$ & & $<.01$ & & $<.01$ & & $<.01$ & & $<.01$ \\
\hline Attending School & & & & & & & & & & & & \\
\hline Yes & $2.82(2.69)$ & & $11.41(5.17)$ & & $2.28(2.12)$ & & $15.74(13.76)$ & & $2.42(2.57)$ & & $1.34(1.49)$ & \\
\hline No & $5.38(3.15)$ & & $14.53(7.08)$ & & $3.69(1.73)$ & & $31.10(17.81)$ & & $5.11(4.50)$ & & $2.89(2.27)$ & \\
\hline $\begin{array}{l}\text { Food security in } \\
\text { past week }\end{array}$ & & $<.01$ & & $<.01$ & & $<.01$ & & $<.01$ & & $<.01$ & & $<.01$ \\
\hline$\geq 5$ days & $2.50(2.59)$ & & $10.66(5.23)$ & & $1.99(2.04)$ & & $12.78(12.24)$ & & $2.14(2.51)$ & & $1.20(1.43)$ & \\
\hline$<5$ days & $4.36(2.79)$ & & $14.56(4.23)$ & & $3.51(1.98)$ & & $28.23(14.02)$ & & $3.84(2.93)$ & & $2.09(1.75)$ & \\
\hline $\begin{array}{l}\text { Any employment } \\
\text { in household }\end{array}$ & & $<.01$ & & $<.01$ & & $<.01$ & & $<.01$ & & $<.01$ & & $<.01$ \\
\hline Yes & $2.51(2.57)$ & & $11.04(5.12)$ & & $2.06(2.07)$ & & $14.46(12.87)$ & & $2.20(2.43)$ & & $1.25(1.47)$ & \\
\hline No & $3.64(2.91)$ & & $12.22(5.61)$ & & $2.84(2.15)$ & & $19.71(16.31)$ & & $2.87(2.80)$ & & $1.61(1.62)$ & \\
\hline $\begin{array}{l}\text { Any welfare grant } \\
\text { in household }\end{array}$ & & $<.01$ & & $<.01$ & & $<.01$ & & $<.01$ & & $<.01$ & & $<.01$ \\
\hline Yes & $2.57(2.61)$ & & $11.14(5.45)$ & & $2.03(2.08)$ & & $14.22(13.76)$ & & $2.11(2.56)$ & & $1.22(1.53)$ & \\
\hline No & $3.37(2.86)$ & & $12.03(5.02)$ & & $2.71(2.12)$ & & $19.05(14.35)$ & & $3.02(2.77)$ & & $1.62(1.55)$ & \\
\hline
\end{tabular}

Note: Depression assessed using the CDI measure; anxiety assessed using the R-CMAS measure; peer problems assessed using the SDQ peer subscale; post traumatic stress symptoms assessed using the Child PTSD Checklist; delinquency assessed using the CBCL subscale; conduct problems assessed using the SDQ Conduct Problems subscale. All $p$-values associated with independent sample t-test. 
Table 3. Multivariate associations between orphanhood by AIDS, orphanhood by other causes, and psychological outcomes, controlling for sociodemographic cofactors and poverty-related variables

\begin{tabular}{|c|c|c|c|c|c|c|c|c|c|c|c|c|}
\hline \multirow[b]{3}{*}{$\begin{array}{l}\text { Orphanhood } \\
\text { by AIDS }\end{array}$} & \multicolumn{2}{|c|}{ Depression $^{1}$} & \multicolumn{2}{|c|}{ Anxiety $^{2}$} & \multicolumn{2}{|c|}{ Peer Problems ${ }^{3}$} & \multicolumn{2}{|c|}{ PTSD $^{4}$} & \multicolumn{2}{|c|}{ Delinquency $^{5}$} & \multicolumn{2}{|c|}{ Conduct Problems } \\
\hline & Model 1 & $\overline{\text { Model } 2}$ & Model 1 & Model 2 & Model 1 & Model 2 & Model 1 & Model 2 & Model 1 & $\overline{\text { Model } 2}$ & Model 1 & $\overline{\text { Model } 2}$ \\
\hline & $.117 * *$ & .055 & .042 & -.019 & $.174 * *$ & $.131 * *$ & $.195^{* *}$ & $.118^{* *}$ & $.072 *$ & .016 & $.076^{*}$ & .030 \\
\hline $\begin{array}{l}\text { Orphanhood } \\
\text { by other } \\
\text { causes }\end{array}$ & .011 & -.018 & -.016 & -.044 & .030 & .010 & .065 & .030 & -.010 & -.035 & -.012 & -.032 \\
\hline R-Square & .055 & .094 & .029 & .071 & .058 & .077 & .076 & .132 & .056 & .089 & .037 & .058 \\
\hline $\begin{array}{l}\text { R-Square } \\
\text { change }\end{array}$ & & .040 & & .042 & & .020 & & .056 & & .033 & & .022 \\
\hline F-change & & $40.56 * *$ & & $39.15 * *$ & & $18.88 * *$ & & $57.73 * *$ & & $33.44 * *$ & & $21.04 * *$ \\
\hline
\end{tabular}

* Denotes significance at the 0.05 level

** Denotes significance at the .001 level

Note: Model 1 adjusted for sociodemographic co-factors, described below. Model 2 adjusted for poverty indicators: attending school, food security for $\geq 5$ days in past week, employment in household and any social security transfer in household.

${ }^{1}$ Model 1 controls for age, gender.

${ }^{2}$ Model 1 controls for age, gender.

${ }^{3}$ Model 1 controls for age, household size, $>2$ moves between homes.

${ }^{4}$ Model 1 for age, gender, household size, $>2$ moves between homes.

${ }^{5}$ Model 1 controls for age, gender, migration, $>2$ moves between homes.

${ }^{6}$ Model 1 controls for age, gender, migration 
Figure 1: Mediation Model

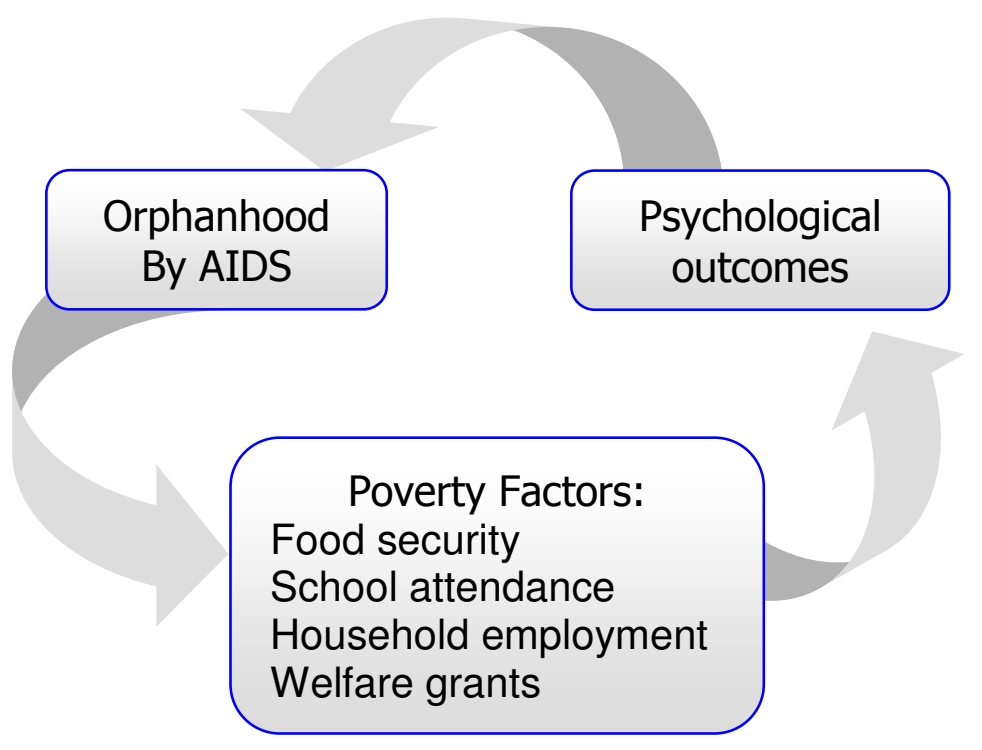


Poverty and AIDS Orphans 25 